\title{
Character and origin of vacuoles induced in mammalian cells by the cytotoxin of Helicobacter pylori
}

\author{
C. E. CATRENICH and M. H. CHESTNUT
}

The Procter and Gamble Company, Miami Valley Laboratories, PO Box 398707, Cincinnati, OH 45239-8707, USA

\begin{abstract}
Summary. Cytotoxic activity of culture supernates of Helicobacter pylori is manifested by vacuolation of mammalian cells in vitro. The formation and maturation of toxin-induced vacuoles in $\mathrm{HeLa}$ cells has been studied to examine the possibility that they are autophagosomal in nature. Observation by light microscopy revealed that vacuoles originate in a perinuclear position, increasing in number and size until cell degeneration and lysis occur after $48 \mathrm{~h}$. Ultrastructural study of mature vacuoles indicated the presence of a bounding membrane with contents consisting of degenerate cytoplasmic components and acid phosphatase activity. Confocal fluorescence imaging demonstrated acridine orange accumulation in the vacuoles of toxin-treated cells, indicating an acidic intravacuolar $\mathrm{pH}$. These features are characteristic of autophagosomes. In addition, the size of vacuoles in living, acridine orange-stained cells tended to be inversely proportional to fluorescence intensity. Fluid phase endocytic markers were observed only rarely within nascent vacuoles. Over the succeeding $24 \mathrm{~h}$, labelling of most vacuoles with these dyes was observed. This, along with the observation of intravacuolar acid phosphatase activity, provides evidence that vacuoles communicate at some point during their development with endocytically derived compartments. These observations provide direct evidence for an autophagic origin of these structures.
\end{abstract}

\section{Introduction}

Helicobacter pylori is a non-invasive gram-negative spiral bacterium that was first identified in 1983 and subsequently implicated in the pathogenesis of gastroduodenal disease, including gastritis and peptic ulcer disease. ${ }^{1-3}$ Cytotoxic activity, manifested by intracytoplasmic vacuolation of mammalian cells in vitro, was identified in broth culture filtrates of $55 \%$ of H. pylori strains. ${ }^{4}$ A high-mol. wt, heat-labile exoprotein which has been purified recently* is believed to be responsible for this phenomenon.

Human and animal studies of the cytotoxin of $H$. pylori provide evidence that suggests a role for the cytotoxin in the pathogenesis of gastroduodenal disease associated with $H$. pylori. Thus, toxigenic strains of $H$. pylori are more virulent for gnotobiotic piglets than non-toxigenic strains, ${ }^{5}$ and are more often associated with peptic ulcer disease than with dyspepsia and gastritis, which are considered to be milder forms of disease. ${ }^{6}$ Furthermore, patients infected with $H$. pylori produce antibody that neutralises cytotoxin activity, ${ }^{7}$ indicating that the cytotoxin is produced in vivo, and vacuolation of gastric epithelial cells is observed in vivo during infection by $H$. pylori. ${ }^{8}$

Little is known of the mechanism by which the toxin

* See note added in proof

Received 21 Jan. 1992; accepted 10 March 1992 induces vacuolation and, ultimately, destruction of mammalian cells or of the clinical relevance of this effect in pathogenesis. Previous ultrastructural studies succeeded in identifying the presence of a bounding membrane around vacuoles induced in vitro in $\mathrm{HeLa}$ cells and organelle remains within the vacuoles. ${ }^{4}$ Preliminary studies have demonstrated the apparent lytic and acidic nature of the toxin-induced vacuoles. ${ }^{9,10}$ Quantitative measurements of neutral red uptake suggest that ammonia generated by urease activity or some other bacterial metabolic process acts to potentiate vacuolation. ${ }^{11}$ Ultrastructural observations of surface epithelium abnormalities have indicated that vacuoles observed in vivo appear to be autolytic in nature. ${ }^{8}$ These observations suggested that toxin-induced vacuoles may have their origin in autophagosomes.

The bounding membranes of autophagic vacuoles are thought to arise from the endoplasmic reticulum (ER), because integral ER membrane proteins have been identified immunochemically in nascent vacuole membranes. ${ }^{12,13}$ The presence of partly digested organelles, lgp 120, and hydrolytic enzyme activity ${ }^{12,13}$ is characteristic of mature autophagic vacuoles, which may arise by fusion of nascent vacuoles with lysosomes, ${ }^{14}$ or by a more complex protein transport and sequestration mechanism. ${ }^{15,16}$ Under normal conditions, autophagosomes presumably recycle cytoplasmic components but they appear rapidly in cells 
exposed to certain stresses, including those that deprive the cell of amino acids. ${ }^{12,13,17}$

We have used morphological techniques to examine the vacuoles and to show that they are autophagic in nature.

\section{Materials and methods}

\section{Organisms and growth media}

H. pylori strain 60190 , a toxigenic human isolate, ${ }^{4}$ was used. It was maintained on Campy Chocolatised Agar supplemented with TVAP (Remel, Lenexa, KS, USA) in a triple-gas incubator (Napco, Tualatin, OR, USA) at $37^{\circ} \mathrm{C}$ under micro-aerobic conditions $\left(\mathrm{O}_{2}\right.$ $5 \%, \mathrm{CO}_{2} 10 \%, \mathrm{~N}_{2} 85 \%$ ). Broth media consisted of Brucella Broth (BBL, Cockeysville, MD, USA) supplemented with fetal bovine serum (FBS, Gibco, Grand Island, NY, USA) at a final concentration of $2 \% \mathrm{v} / \mathrm{v}$. Broth cultures were inoculated with $H$. pylori grown for 3 days on Campy agar and incubated at $37^{\circ} \mathrm{C}$ in a gyratory water bath (New Brunswick Scientific, Edison, NJ, USA) infused with the above gas mixture.

HeLa cells (ATCC CCL 2.2) were cultured in Minimum Essential Medium (MEM) with Earle's salts and 25 mM HEPES (Gibco) supplemented with FBS $5 \% \mathrm{v} / \mathrm{v}, 2 \mathrm{mM} \mathrm{L}$-glutamine and antibiotic-antimycotic mixture (Gibco). Cells were maintained at $37^{\circ} \mathrm{C}$ in a $\mathrm{CO}_{2} 5 \%$ atmosphere.

\section{Production of cytotoxin}

Cytotoxin was prepared and HeLa cells were treated by a modification of the procedure described by Leunk et al. ${ }^{4}$ Briefly, high-mol. wt components ( $>30 \mathrm{kDa}$ ) of broth-culture filtrates of $H$. pylori were concentrated 20 -fold by centrifugation with Centriprep 30 concentrators (Amicon, Danvers, MA, USA). In this way, direct osmotic effects due to low-mol. wt molecules were avoided. Concentrated filtrates were diluted 1 in 10 in six-well tissue culture plates containing glass cover-slips with adherent HeLa cells ( $25 \%$ confluence). The plates were then incubated as above.

\section{Cytochemical staining}

Acridine orange (AO) accumulation was assessed by exposing living HeLa cells, vacuolated by exposure to toxin for $24 \mathrm{~h}$, to AO (Molecular Probes A-1301, Eugene, OR, USA) at a final concentration of $5 \mu \mathrm{g} / \mathrm{ml}$ for $2 \mathrm{~min}$ in MEM. ${ }^{18,10}$ Cover-slips bearing cells were then rinsed three times in Dulbecco's phosphatebuffered saline (PBS), mounted on microscope slides at $25^{\circ} \mathrm{C}$ and observed immediately. All observations were recorded during the $10-15 \mathrm{~min}$ that cells retained normal morphology under these conditions.

Movement of Lucifer Yellow carbohydrazide (LY, Molecular Probes L-1177) or fluorescein isothio- cyanate (FITC)-dextran (Sigma FD-70S, St Louis, MO, USA) into the vacuoles was assessed by exposing $\mathrm{HeLa}$ cells to these dyes simultaneously with the addition of toxigenic filtrate. LY was applied at a final concentration of $0.5 \mathrm{mg} / \mathrm{ml}$ in PBS and FITC-dextran at a final concentration of $1 \mathrm{mg} / \mathrm{ml}$ in PBS. The cells were incubated for $30 \mathrm{~min}-22 \mathrm{~h}$ as described above, rinsed four times with PBS, mounted on microscopes slides at $25^{\circ} \mathrm{C}$ and observed immediately.

Specimens for acid phosphatase cytochemistry were prepared according to Griffiths et al ${ }^{20,21}$ Briefly, cells were fixed in glutaraldehyde $0.5 \%$ in $100 \mathrm{~mm}$ PIPES buffer $(\mathrm{pH} 7.0$ ) for $15 \mathrm{~min}$ at room temperature, washed with $10 \mathrm{mM}$ sodium acetate buffer ( $\mathrm{pH} 5 \cdot 0$ ) then incubated in a mixture of $\beta$-glycerophosphate and lead nitrate in the acetate buffer at $37^{\circ} \mathrm{C}$ for $60 \mathrm{~min}$. In controls, $\beta$-glycerophosphate substrate was omitted or enzyme activity was inhibited with $10 \mathrm{~mm}$ sodium fluoride added to the reaction mixture. Cells were post-fixed, embedded and observed as described below.

\section{Microscopy}

Laser-scanned confocal images of AO, LY and FITC-dextran fluorescence were obtained with a Sarastro 2000 confocal laser scanning microscope system (Molecular Dynamics, Sunnyvale, CA, USA) operating with $488 \mathrm{~nm}$ argon ion laser illumination. Fluorescence filtration for all probes was achieved with a $510 \mathrm{~nm}$ dichroic mirror and a $510 \mathrm{~nm}$ longpass barrier filter. Simultaneous non-confocal transmitted light images were obtained for some studies with a transmitted light detector.

For conventional light microscopy, cells were observed with an Olympus IMT-2 inverted research microscope (Olympus Optical Co., Tokyo, Japan).

For transmission electronmicroscopy (TEM), cells were fixed for $30 \mathrm{~min}$ at room temperature with glutaraldehyde $3 \%$ in $100 \mathrm{~mm}$ cacodylate buffer $(\mathrm{pH}$ 7.2 ) containing sucrose $5 \% \mathrm{w} / \mathrm{v}$. They were then rinsed in the same buffer, post-fixed with $\mathrm{OsO}_{4} 1 \%$ in $100 \mathrm{~mm}$ cacodylate buffer (pH 7.2) for $60 \mathrm{~min}$, dehydrated in increasing concentrations of ethanol, and embedded in Spurr's resin..$^{22}$ Specimens were sectioned with a Reichert Ultracut E ultramicrotome (ReichertJung division of Leica, Germany). Silver-gold sections were stained with uranyl acetate and lead citrate in an LKB Ultrostainer (Pharmacia-LKB, Uppsala, Sweden). Sections were examined with a Zeiss EM902 transmission electronmicroscope (Carl Zeiss, Oberkochen, Germany) at $80 \mathrm{kV}$ in the zero-loss brightfield mode.

\section{Results}

\section{Examination of vacuole formation}

Vacuoles initially appeared in HeLa cells by light 

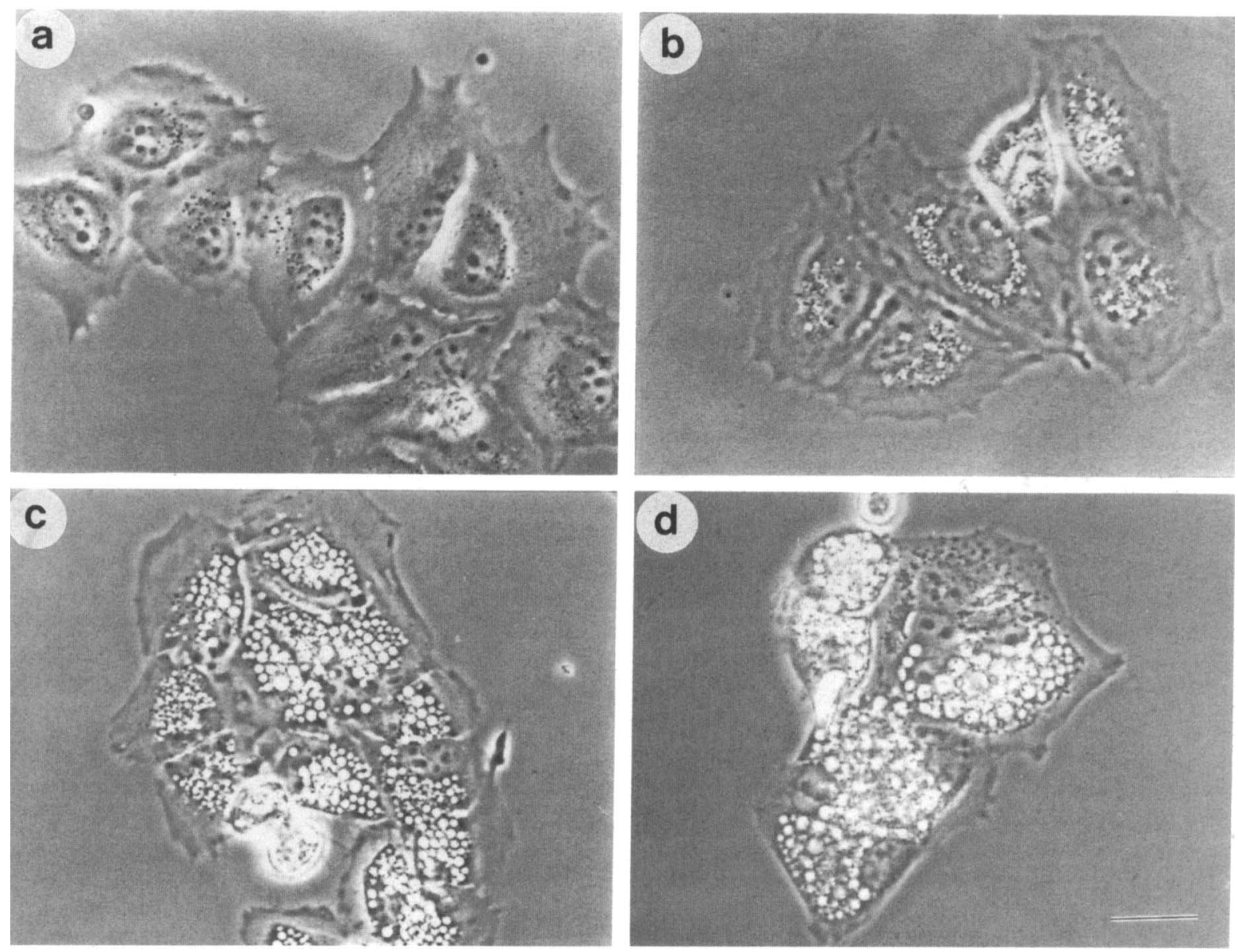

Fig. 1. Light micrographs of HeLa cells (a) observed immediately after treatment with cytotoxin and after incubation for (b) $3 \mathrm{~h}$, (c) $6 \mathrm{~h}$ and (d) 48 h. Bar, $25 \mu \mathrm{m}$.
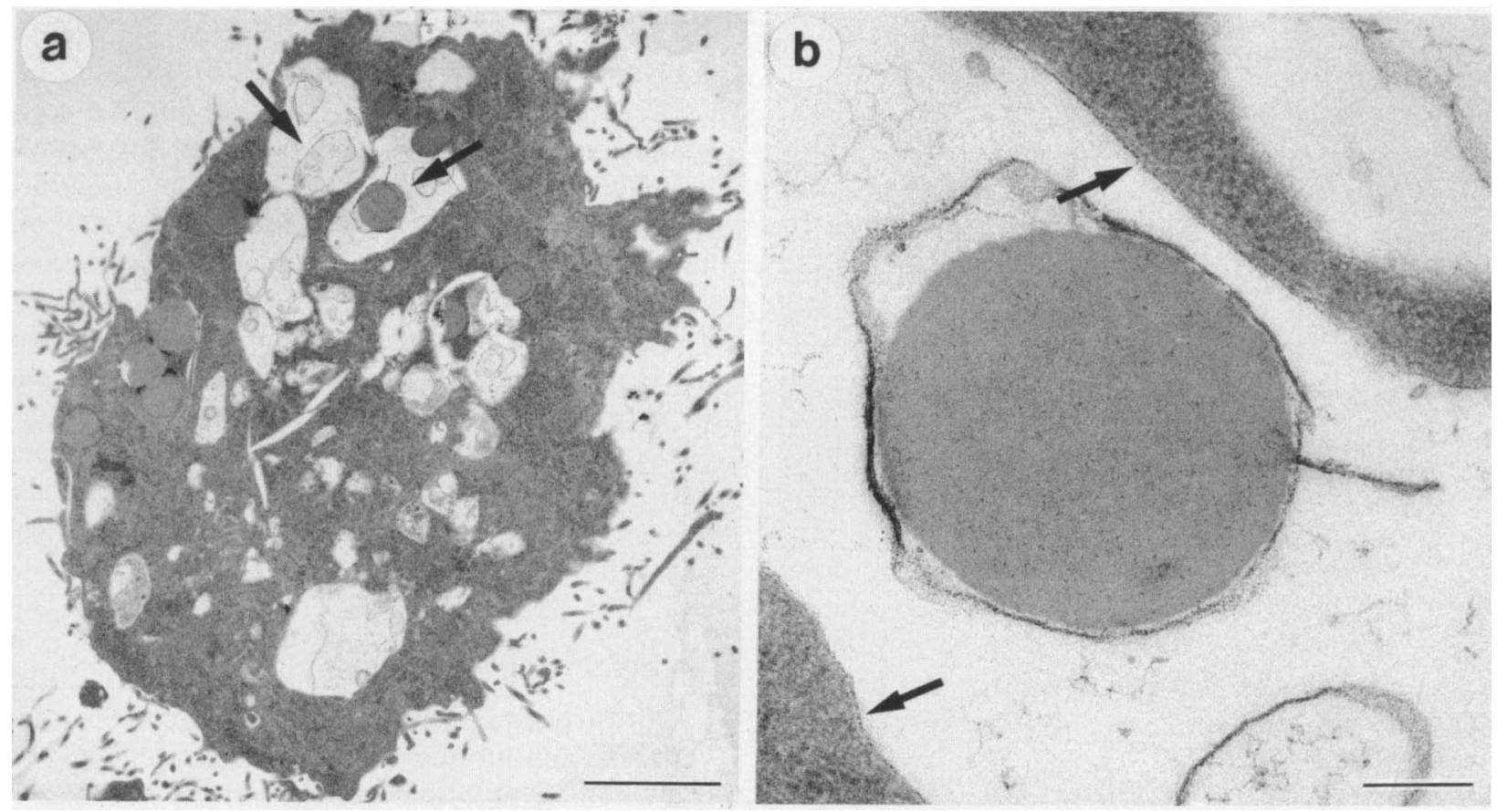

Fig. 2. Transmission electronmicrographs of cytotoxin-treated HeLa cells. (a) Cytoplasmic components are visible within the vacuoles (arrows). (b) Bounding membrane (arrows). Bar in a, $5 \mu \mathrm{m}$, in b, $250 \mathrm{~nm}$.

microscopy $3 \mathrm{~h}$ after treatment with a cytotoxin preparation (fig. 1). In contrast to untreated control cells (fig. 1a), nascent vacuoles initially appeared to concentrate in the perinuclear region (fig. 1b). After $6 \mathrm{~h}$, the vacuoles had increased in number and size, occupying much of the cytoplasm (fig. 1c). After 

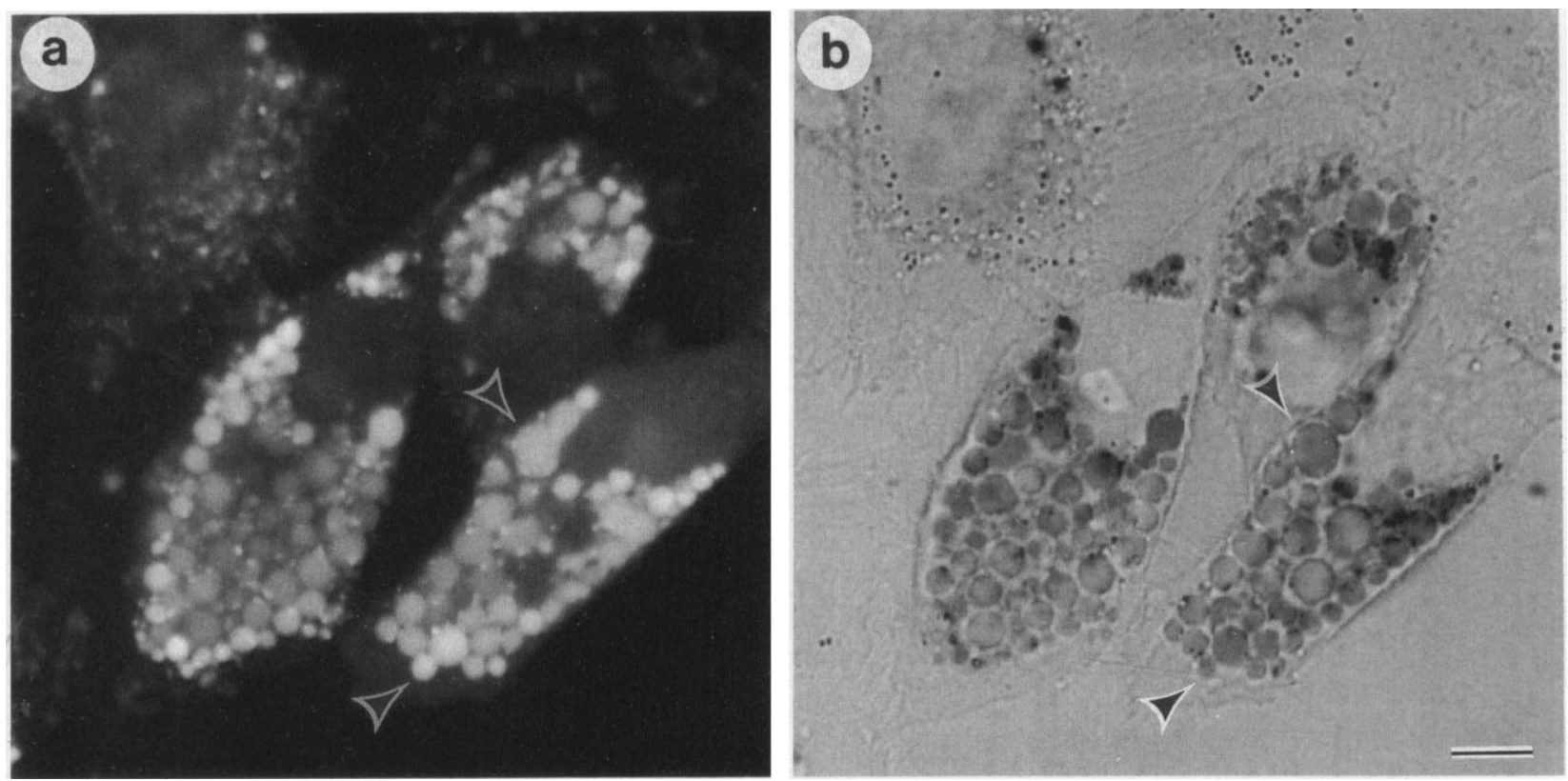

Fig. 3. Confocal fluorescence (a) and transmitted brightfield (b) images of cytotoxin-treated, acridine orange-stained HeLa cells. Vacuoles have accumulated acridine orange, as indicated by fluorescence (paired arrows in a and b). Smaller endosomal and lysosomal compartments with uniform intense fluorescence are also visible. The non-vacuolate cell in the upper left portion of the micrographs is representative of the appearance of cells not treated with toxin. Bar, $10 \mu \mathrm{m}$.

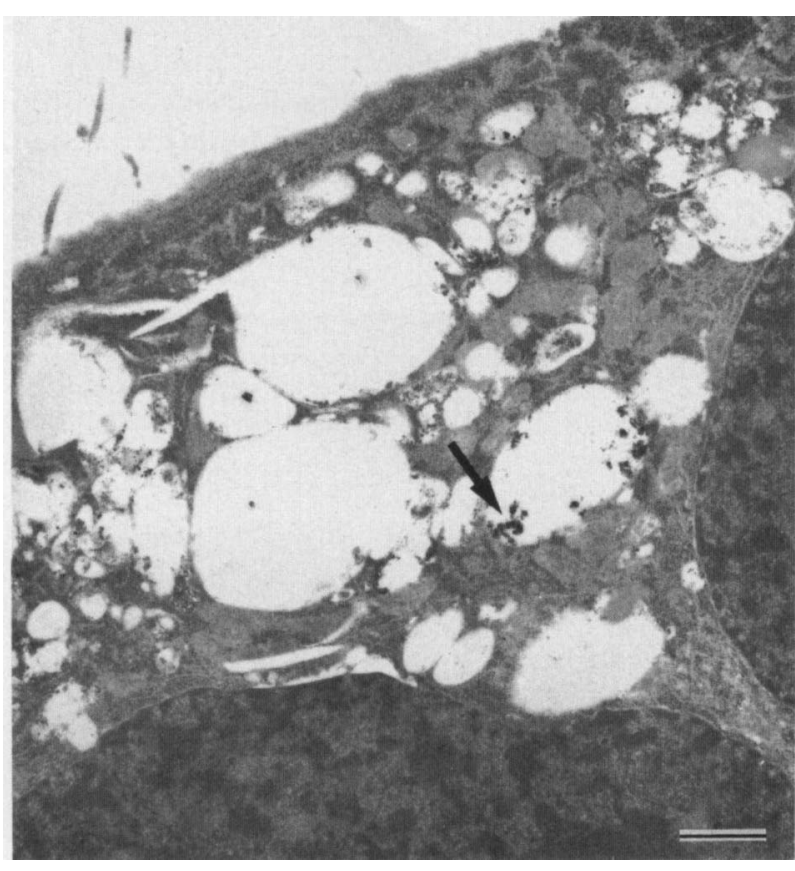

Fig. 4. Transmission electronmicrograph of a cytotoxin-treated HeLa cell stained for acid phosphatase activity. Arrow indicates reaction product. Bar, $1 \mu \mathrm{m}$.

incubation for $48 \mathrm{~h}$, vacuole and HeLa cell degeneration was apparent with loss of cell integrity (fig. 1d).

\section{Ultrastructure of vacuolated cells}

HeLa cells exposed to a cytotoxin preparation for $24 \mathrm{~h}$ revealed normal features of cultured mammalian cells along with cytotoxin-induced intracytoplasmic vacuoles (fig. 2). The vacuoles were numerous and ranged in size from $0.5 \mu \mathrm{m}$ to $3.0 \mu \mathrm{m}$. Cytoplasmic components were apparent within the vacuoles (arrows, fig. 2a) which were enclosed within a membrane (arrows, fig. 2b). Vacuolar shrinkage, resulting from processing for TEM, accounts for their nonspherical appearance.

\section{Intravacuolar $p H$}

Two main observations were made by confocal fluorescence imaging of $\mathrm{AO}$-stained $\mathrm{HeLa}$ cells treated with cytotoxin for $24 \mathrm{~h}$ (fig. 3). First, fluorescence at wavelengths $>510 \mathrm{~nm}$ from structures (fig. 3a) corresponding to vacuoles in the transmitted brightfield image (fig. 3b), indicated accumulation of AO, and hence the acidic $\mathrm{pH}$ of these organelles. Second, fluorescence intensity generally varied inversely with vacuolar size. The smallest endosomes and lysosomes were also visible and fluoresced more intensely. Lysosomes and endosomes appeared with uniform fluorescence intensity in non-vacuolate cells (fig. 3a, upper left). These structures were not usually visible in transmitted brightfield images of the same cells (fig. 3b).

\section{Enzymic activity of vacuolar contents}

Ultrastructural acid phosphatase cytochemistry with lead capture reagents showed enzymic activity, characteristic of lysosomes, within the vacuoles induced by the incubation of HeLa cells for $24 \mathrm{~h}$ with the cytotoxin (fig. 4). Enzymic activity was demonstrated by the production of electron-dense reaction product (arrow) in vacuoles incubated with the $\beta$ glycerophosphate and lead nitrate substrate mixture. The reaction product was not observed when $\beta$ - 

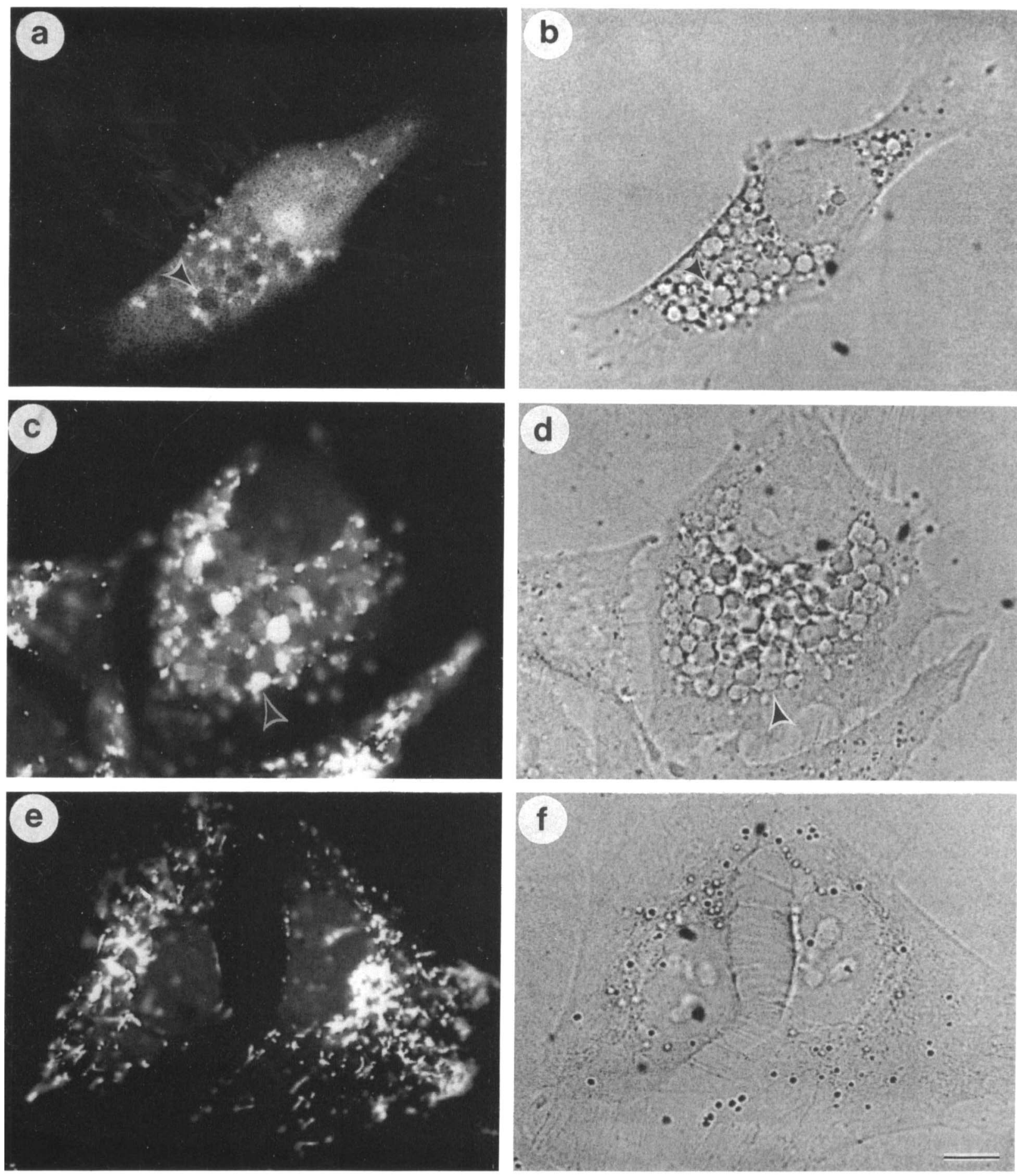

Fig. 5. Confocal fluorescence (a, c, e) and transmitted brightfield $(b, d, f)$ images of cytotoxin-treated, lucifer yellow-stained HeLa cells after $3 \mathrm{~h}(\mathbf{a}, \mathbf{b})$ and $24 \mathrm{~h}(\mathbf{c}, \mathbf{d})$ of simultaneous incubation with a cytotoxin preparation and Lucifer Yellow. Paired arrowheads in $\mathbf{a}$ and $\mathbf{b}$ indicate unlabelled vacuoles and the corresponding brightfield image. Paired arrowheads in $\mathbf{c}$ and $\mathbf{d}$ indicate fluorescently-labelled vacuoles and the corresponding brightfield image. Untreated $24 \mathrm{~h}$ control cells show intense labelling of endocytic vesicles (e, f). Bar, $10 \mu \mathrm{m}$.

glycerophosphate was omitted, or when sodium fluoride was used to inhibit acid phosphatase activity (data not shown).

\section{Contribution of fluid phase endocytosis to vacuole formation}

Small vesicles in the peripheral cytoplasm became fluorescently labelled within $30 \mathrm{~min}$ of addition of LY to HeLa cells in the presence or absence of toxin. After co-incubation of a cytotoxin preparation and LY with HeLa cells for $3 \mathrm{~h}$, prominent labelling of endosomes was observed resulting from fluid phase uptake of the dye. At this time, most cytotoxin-induced vacuoles were not labelled with LY (arrowheads figs. 5a and b). The frequency of vacuole labelling increased over the succeeding $21 \mathrm{~h}$, until after $24 \mathrm{~h}$ in the presence of both LY and cytotoxin, LY had accumulated to varying degrees in nearly all vacuoles (figs. $5 \mathrm{c}$ and $\mathrm{d}$ ). When untreated cells were labelled by the same technique, 
lysosomes and endosomes appeared with a uniform intensity of fluorescence (figs. 5e and f). Similar observations were made with FITC-dextran as the fluorescence probe for endocytosis.

\section{Discussion}

Identification of the mechanism of action of the cytotoxin of $H$. pylori is an important pre-requisite for clarifying its involvement in gastroduodenal disease. The vacuoles induced by the cytotoxin in vitro were, therefore, characterised cytochemically and ultrastructurally to understand better the mechanism of action of the cytotoxin and its potential clinical relevance. Vacuolation of mammalian cells have been reported to follow nutrient deprivation, chemical exposure and bacterial toxin activity. ${ }^{12,23,24}$ One such vacuole type, the autophagosome, normally contributes to the recycling of cytoplasmic components, but appears rapidly and in excessive numbers in cells exposed to metabolic stress ${ }^{12,13,17}$ and is believed to originate by fusion of ER-derived vacuoles and lysosomes. ${ }^{12,13}$ Autophagosomes are acidic and contain acid phosphatase activity and cytoplasmic debris. The present study shows that toxin-induced vacuoles resemble autophagosomes in the nature of their contents and their communication with the endo-lysosomal pathway during maturation.

The acidic nature of toxin-induced vacuoles was demonstrated by the accumulation of the membranepermeant, fluorescent weak base AO whose fluorescence becomes red-shifted at high local dye concentration..$^{25} \mathrm{~A}$ tendency was noted for larger vacuoles to be less intensely labelled, indicating a higher $\mathrm{pH}$ within these structures. This observation may reflect the accumulation in situ of a weak base, possibly ammonia, produced before or during incubation of the HeLa cells with the cytotoxin preparation. Others have shown that the vacuolating activity of cytotoxin preparations maybe potentiated by urease-mediated ammonia production. ${ }^{11}$ When weak bases diffuse into acidic compartments, they raise the $\mathrm{pH}$, with the result that a greater proportion of weak base molecules become protonated. Once protonated they are no longer membrane permeable, become trapped, and can lead to osmotic swelling of the compartment. ${ }^{26}$ However, it is possible that osmotic swelling from other causes might produce the observed lowering of fluorescence intensity among the vacuoles, since the resulting volume increase could, in the absence of ion pumping, raise the intravacuolar $\mathrm{pH}$.

The presence of acid phosphatase activity within some cytotoxin-induced vacuoles, demonstrated by classical techniques, ${ }^{20,21}$ indicates contact with lysosomal compartments during vacuole formation and maturation. Current opinion is divided about the origin of so-called primary and secondary lysosomes, ${ }^{14,15}$ but the presence of hydrolytic enzyme activity within the toxin-induced vacuoles strongly indicates a catabolic function. This is consistent with our observations and those of others, of partly digested organelles within the vacuoles. ${ }^{4,80}$ It is tempting to conjecture that acid phosphatase-negative vacuoles are immature in a way analogous to immature autophagosomes. However, autophagic vacuoles in some systems mature and acquire acid phosphatase activity within 15-30 $\mathrm{min},{ }^{12,13}$ whereas we found only partial labelling of the vacuole population after toxin treatment for $24 \mathrm{~h}$.

Based on the above evidence, endosomes or secondary lysosomes are likely to play a role in the formation and maturation of cytotoxin-induced vacuoles. This hypothesis was tested with fluorescent probes of fluid phase endocytosis. When HeLa cells were exposed simultaneously to LY or FITC-dextran and cytotoxin preparations, labelling of the vacuoles with these probes occurred rarely after exposure for $2 \mathrm{~h}$, was more common at $3-6 \mathrm{~h}$ and was virtually universal after $24 \mathrm{~h}$. Although nearly all vacuolate cells had some labelled vacuoles, after longer exposure not all vacuoles in a given cell were labelled. This strongly suggests that cytotoxin-induced vacuoles eventually communicate with endosomally-derived compartments.

Taken together, these observations support the hypothesis that the vacuoles induced by the cytotoxin of $H$. pylori are autophagosomal in nature. They presumably arise from toxin-induced intracellular dysfunction, although the mechanism is at present unknown. Identification of ER-specific markers in the cytotoxin-induced vacuole membrane and observation of early double membrane-bound vacuoles, would lend strong support to our hypothesis. Studies to clarify when nascent vacuoles become acidic and acid phophatase-positive would help to determine whether these events depend on communication with endocytically-derived compartments, but the timing of vacuole formation would make such studies difficult. We suggest that the vacuoles may release hydrolytic enzymes upon enlargement and rupture, thus contributing to the autolysis of affected cells as a function of time, as is indicated by light microscope observations. Such a phenomenon in vivo is likely to contribute to the genesis of gastroduodenal pathology associated with infection by $H$. pylori and may, therefore, be clinically relevant.

\section{Note added in proof}

The purification of the toxin was reported after submission of this paper. Cover TL, Blaser MJ. Purification and characterization of the vacuolating toxin from Helicobacter pylori. J Biol Chem 1992; 267: 10570-10575. 


\section{References}

1. Blaser MJ. Gastric Campylobacter-like organisms, gastritis, and peptic ulcer disease. Gastroenterology 1987; 93: 371-383.

2. Goodwin CS, Armstrong JA, Marshall BJ. Campylobacter pyloridis, gastritis and peptic ulceration. J Clin Pathol 1986; 39: 353-365.

3. Marshall BJ, Armstrong JA, McGechie DB, Glancy RJ. Attempt to fulfil Koch's postulates for pyloric campylobacter. Med J Aust 1985; 142: 436-439.

4. Leunk RD, Johnson PT, David BC, Kraft WG, Morgan DR. Cytotoxic activity in broth-culture filtrates of Campylobacter pylori. J Med Microbiol 1988; 26: 93-99.

5. Eaton KA, Morgan DR, Krakowka S. Campylobacter pylori virulence factors in gnotobiotic piglets. Infect Immun 1989; 57: 1119-125.

6. Figura N, Guglielmetti P, Rossolini A et al. Cytotoxin production by Campylobacter pylori strains isolated from patients with peptic ulcers and from patients with chronic gastritis only. J Clin Microbiol 1989; 27: 225-226.

7. Leunk RD, Ferguson MA, Morgan DR, Low DE, Simor AE. Antibody to cytotoxin in infection by Helicobacter pylori.J Clin Microbiol 1990; 28: 1181-1184.

8. Tricottet V, Bruneval P, Vire O et al. Campylobacter-like organisms and surface epitheloium abnormalities in active, chronic gastritis in humans: an ultrastructural study. Ultrastruct Pathol 1986; 10: 113-122.

9. Catrenich CE, Chestnut MH. Characterization of the vacuoles induced by the cytotoxin of Helicobacter pylori. Abstracts of the 91st Annual Meeting of the American Society for Microbiology 1991: Abstract B-212, 61.

10. Chestnut MH, Catrenich CE. Vacuoles induced in mammalian cells by Helicobacter pylori are acidic organelles. Proceedings of the XIIth International Congress for Electron Microscopy 1990: 168 (Abstract).

11. Cover TL, Puryear W, Perez-Perez GI, Blaser MJ. Effect of urease on HeLa cell vacuolation induced by Helicobacter pylori cytotoxin. Infect Immun 1991; 59: 1264-1270.

12. Dunn WA. Studies on the mechanisms of autophagy: formation of the autophagic vacuole. J Cell Biol 1990; 110: 1923-1933.
13. Dunn WA. Studies on the mechanisms of autophagy: maturation of the autophagic vacuole. $J$ Cell Biol 1990; 110: 1935-1945.

14. Arstila AU, Trump BF. Studies on cellular autophagocytosis. The formation of autophagic vacuoles in the liver after glucagon administration. Am J Pathol 1968; 53: 687-733.

15. Hubbard AL. Endocytosis. Curr Opin Cell Biol 1989; 1: 675-683.

16. Kornfeld S. Trafficking of lysosomal enzymes. FASEB J 1987; 1: $462-468$

17. DeDuve C, Wattiaux R. Functions of lysosomes. Annu Rev Physiol 1966; 28: 435-492.

18. Matteoni R, Kreis TE. Translocation and clustering of endosomes and lysosomes depends on microtubules. J Cell Biol 1987; 105: 1253-1265.

19. Plant AL, Benson DM, Smith LC. Cellular uptake and intracellular localization of benzo(a)pyrene by digital fluorescence imaging microscopy. J Cell Biol 1985; 100: 1295-1308.

20. Griffiths GW. Transport of glial cell acid phosphatase by endoplasmic reticulum into damaged axons. $J$ Cell Sci 1979; 36: 361-389.

21. Griffiths G, Quinn P, Warren G. Dissection of the golgi complex. 1. Monensin inhibits the transport of viral membrane proteins from medial to trans golgi cisternae in baby hamster kidney cells infected with Semliki forest virus. J Cell Biol 1983; 96: 835-850.

22. Spurr AR. A low-viscosity expoxy resin embedding medium for electron microscopy. J Ultrastruct Res 1969; 26: 31-43.

23. Mitchener JS, Shelburne JD, Bradford WD, Hawkins HK. Cellular autophagocytosis induced by deprivation of serum and amino acids in HeLa cells. Am J Pathol 1976; 83: 485-498.

24. Woods DE, Hwang WS, Shahrabadi MS, Que JU. Alteration of pulmonary structure by Pseudomonas aeruginosa exoenzyme S. J Med Microbiol 1988; 26: 133-141.

25. Tsien RY. Fluorescent indicators of ion concentrations. In: Taylor DL, Wang Y-L (eds) Methods in cell biology, vol 30. Academic Press, Inc. 1989: 127-156.

26. Cain CC, Murphy RF. Growth inhibition of 3T3 fibroblasts by lysosomotropic amines: correlation with effects on intravesicular pH but not vacuolation. J Cell Physiol 1986; 129 : 65-70. 